\title{
Cultivating total innovation for operational and adaptation excellence
}

\author{
KOSTAS N. DERVITSIOTIS
}

\begin{abstract}
Purpose of the paper: Since the late 1970's, several significant developments in technology, geopolitics and the world economy have increased complexity in almost every sphere of human activity. As a result, formerly successful strategies have become ineffective. The same applies for hard-to-change pyramid-shaped organizational structures in business and government organizations. In particular, frameworks of performance excellence related to self-assessment and quality awards no longer serve management adequately because consumer preferences, the nature of competition and the sources of competitive advantage shift in a continually evolving environment. To survive, organizations must adapt to emerging conditions. Given these premises, this study intends to expand the traditional Total Quality Management (TQM) approach and proposes a new adaptive TQM framework to manage system complexity through innovation.

Methodology: A literature review analysis serves as a basis to identify the reasons for the increased complexity and to highlight the limits of the traditional TQM approach.

Results: The study identifies two major facets of quality that should be included in the new TQM framework: quality of innovation and quality of the organization design. This innovative adaptive approach for long-term excellence is complementary to the conventional management approach for short-term excellence.

Practical implications: The new measures of performance for excellence must go beyond short-term economic performance and "bottom-line" metrics. A firm's level of success must also include metrics for its landscape fitness, i.e. its capacity to generate value in the future for its stakeholders (customers, workers, owners and others) and adapt as the environment changes.
\end{abstract}

Key words: total innovation; complexity; organizational design; Total Quality Management

\section{Introduction}

The relentless changes that threaten the very survival of contemporary organizations originate primarily in the rapid developments of technology (computers, telecom-munications, molecular biology and others. All of them lead to

\footnotetext{
Professor Emeritus - University of Piraeus - Athens - Greece

e-mail: knderv@ath.forthnet.gr
}

sinergie, rivista di studi e ricerche

n. 93, Gennaio-Aprile 2014, pp. 19-31

ISSN 0393-5108 - DOI 10.7433/ s93.2014.03 
increased economic, social and political interconnectivity, increased complexity, increased uncertainty and environmental volatility. Such trends render forecasting the future, as a basis for planning and control, a pointless exercise. The only way for an organization to survive as a "species" in this new environment is to become adaptive to emerging conditions, a transformation that becomes the new imperative for the $21^{\text {st }} \mathrm{C}$. (Dervitsiotis, 2007).

Leadership must now manage increasing levels of internal and external complexity determined by the number of interactions among the parts of an organization inside its boundary and additional ones in its operational (customers, suppliers, competitors, etc.) and its extended environment (government at local, regional and local levels, industry regulations, practices and others). The key types of complexity management must address include strategic complexity which encompasses a firm's external environment and operating complexity associated with the level of difficulty in solving problems within the firm by individuals, teams, or committees. We also observe a variety of complexity kinds related to the built-in or inherent complexity determined by its minimum essential components, design complexity deriving from design choices, dysfunctional complexity from inefficient processes, inadequate skill-sets and process disconnects and imposed complexity associated with rules and restrictions imposed by external actors, such as the government, industry bodies, trade organizations and others.

\section{Reasons for the trend of increasing system complexity}

Organizations are open systems in continuous interaction with one or more parts of their environment (see Figure 1). With changes in the environment generated by advances in technology, by more liberal trade regulations, or the emergence of powerful new players such as the BRIC countries (Brazil, Russia, India, and China), there is a need to continually adapt through continual internal adjustments or less frequently with a more drastic reorganization.

Competing in the global economy presents a significant challenge for leadership which has must address multiple issues generated by an environment with increasing complexity. For an organization to survive in a changing environment with greater complexity, it must develop and maintain the same or more degrees of freedom to act as those encountered in its emerging environment (Ashby, 1958). To do so effectively, leadership must first address the need to modify the organizational architecture to handle new critical tasks. These may refer to operating an offshore production unit in a different culture, or marketing in emerging markets, which may call for new business models, for new product design based on cost to compete, such as those in China, India, Brazil and others, as described in "Building a second home in China" (Galvin, et al., 2010 ).

With the same pyramid-shaped organization design and leadership placed at the top, it is very difficult if not impossible to make an organization adaptive enough to adapt to new conditions and identify those value-adding opportunities that will 
create the much-needed future revenue streams. It is no longer sufficient for survival to relying on efficiency-oriented policies, such as laying off personnel in large numbers to reduce costs. As the technological and global economic forces are transforming the business environment we need a value-to-customer approach calling for a living systems view of organizations and their environment. The best way organizations can survive competitive pressures involves:

1. Identifying promptly emerging opportunities by sensing the way customer priorities are shifting to new products and services which offer greater value and satisfy their needs along the price-quality-time criteria that form the basis of their corporate strategy.

2. Changing the organizational design, which also involves new leadership roles and responsibilities, so as to attain an optimum fitness with emerging business environment or landscape.

For adaptation to proceed effectively, an organization must make the transition from a stable state, reached in a period of no significant environmental change, to a fluid state that allows the needed transformation in its structure and behavior patterns.

Moving an organization to the "edge of chaos", a condition between stability and complete randomness or chaos, is essential for sustainable excellence in performance (Dervitsiotis, 2003).

\section{Expanding the conventional tqm to manage greater complexity}

For TQM to maintain its relevance and vitality in the present conditions of rapid change, it is essential to expand its boundaries and enable shifting continually its focus to the strategic task of greatest importance. In the short-run leadership must focus on the need to execute well the current strategy and attain operational excellence.

This is the domain of conventional TQM as it was developed for conditions of stability in the 60's with little or predictable change in the environment until the late 1970's. Here the emphasis of TQM was on product and process quality, aiming to minimize variation in all factors that had an impact on quality. The conventional TQM approach has been very successful as long as quality was the key strategic variable for differentiation versus the competition.

For TQM to develop again the momentum it began to lose in the 90's, it must become relevant again by allowing the concept of quality to evolve making it relevant to current conditions as shown in Figure 1. With the dramatic changes in technology (internet), geopolitics (fall of Berlin Wall) and the onset of globalizations from deregulation of trade that begun in the 1980's the pace of change in the external environment could no longer remain stable. 
Fig. 1: Evolution in the concept of quality

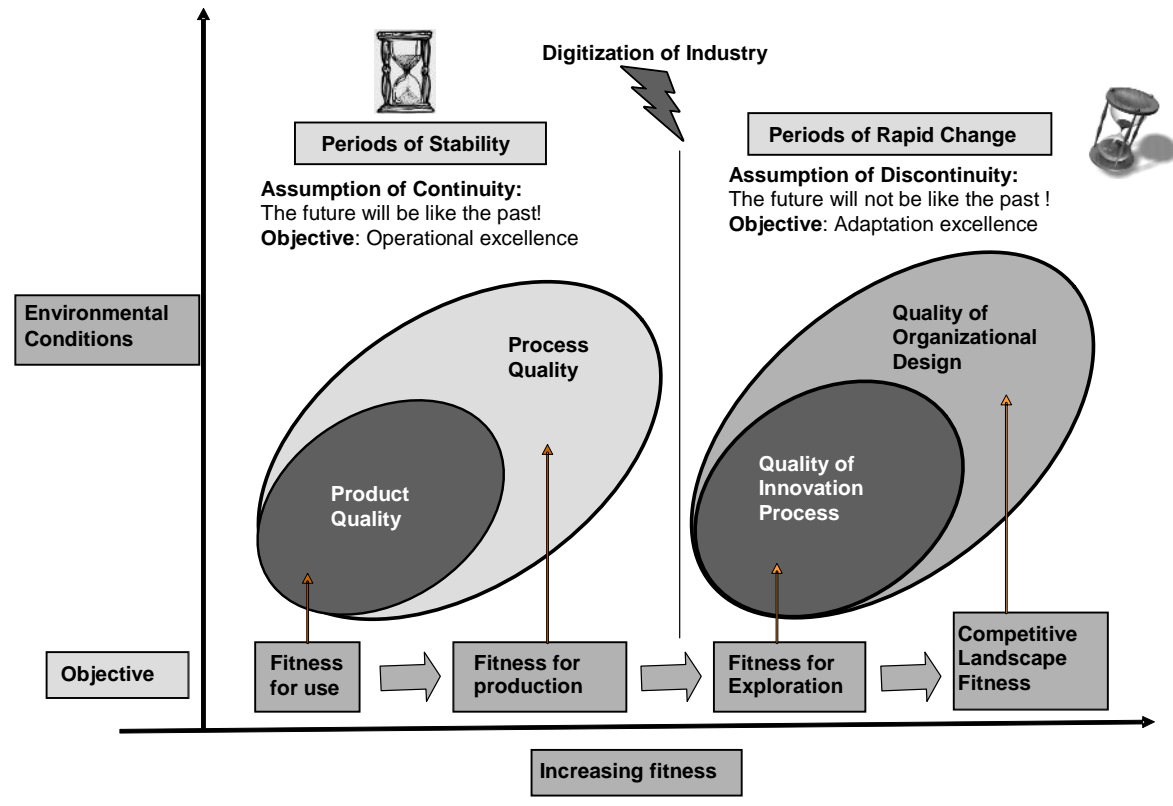

Source: Authors' elaboration

Leadership during periods of rapid change, rather than focusing on product and process quality, essential for survival to compete, must also explore the emerging competitive landscape searching for new sources of value and revenue generation.

This involves the creation of new products or services for new and old needs and for new processes that can produce them at a competitive costs in both old and emerging markets. Gary Hamel in a recent interview points out that in today's conditions of rapid change, the concentration of leadership at the top of the pyramid creates insurmountable obstacles in creating adaptive organizations for the "creative economy".

This comes about because a leadership concentrated at the top lacks ".. the needed intellectual diversity, the bandwidth and the time to make all the needed critical decisions..." As a result most needed changes often come too late, are infrequent and convulsive (Hamel, 2013). In this new era, the innovation of new products, new processes and new business models has become the new competitive edge in global markets, replacing quality which now became a prerequisite for success in the global economy.

Continuous improvement of a product rendered less valuable or obsolete by a new innovation can no longer be viewed as a viable strategic option. 


\section{An innovation-based approach for coping with greater complexity}

During the preceding century-long industrial age, management operated under conditions of relative certainty and stability. The future was expected to be similar to the past. With a focus on a business strategy of "low-cost" or "differentiation" (Porter, 1985), plans were prepared to guide business activities based on a forecast of future demand. In such a relatively stable environment, various methods were developed and refined to plan, coordinate, and control activities to satisfy this expected demand. For management this was a period similar to that of classic or Newtonian physics in science. Total quality management (TQM), Lean Management and Six Sigma represent the best of company-wide approaches developed for such stable environmental conditions.

Fig. 2: Expanding TQM boundaries to managing effectively greater complexity

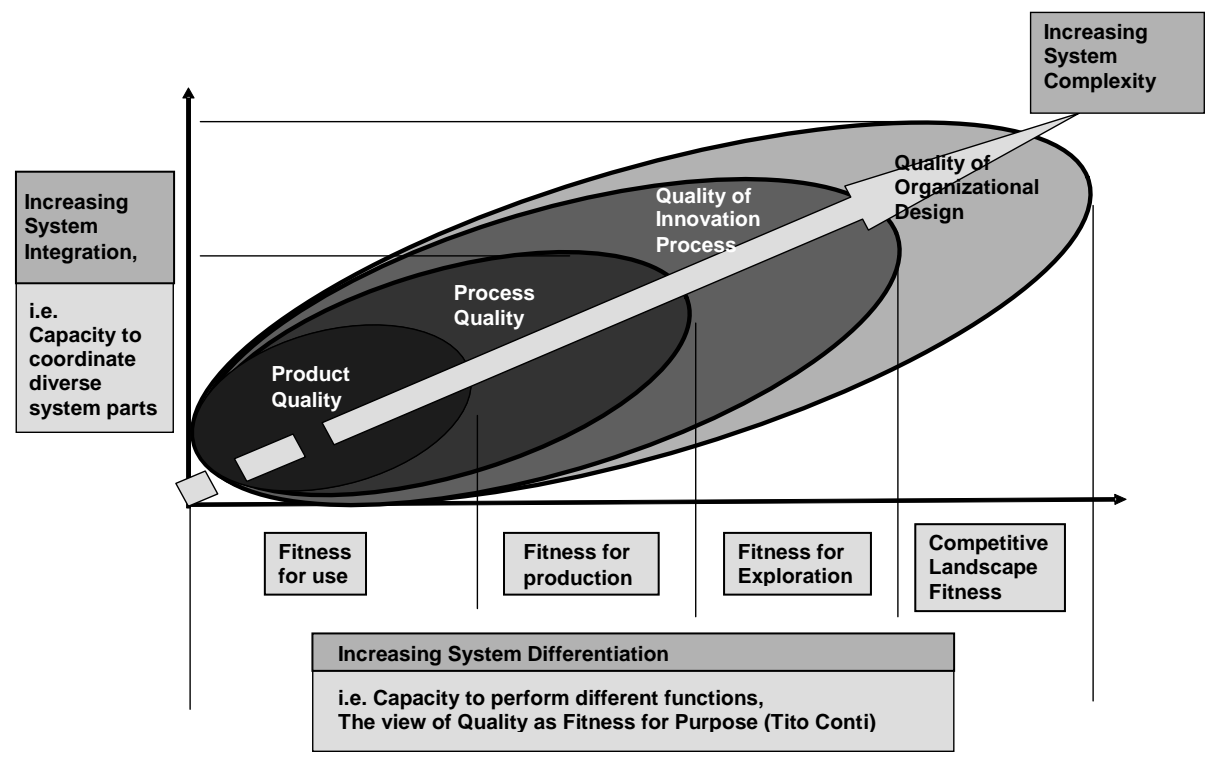

Source: Authors' elaboration

In the present era of a global economy with never-ending uncertainty, as customer expectations and preferences keep changing, the focus of searching for new opportunities that generate new revenues and profits shifts from quality excellence to innovation excellence in order to meet emerging human needs and challenges from new unknown competitors. Quality still remains very important, but is now necessary but not sufficient in providing competitive advantage, as was the case in previous decades of greater environmental stability (see Figure 2). 


\section{Quality of innovation}

In order for an organization to develop and maintain a high quality of its innovation process, it must have a strong capability, following a significant change, to sense the promising opportunities that will create new wealth in the emerging competitive environment. This requires management to address two additional basic tasks.

1. The analysis of incoming signals in order to detect from weak signals which patterns of change in the environment suggest value-creation opportunities from new products or services, from new processes or from new ways of doing business, i.e. from new business models.

This systematic search for new emerging opportunities a firm must do before competitors do the same, otherwise the potential benefits from a new innovation are diffused to many competitors. To avoid loosing sight of new opportunities with great potential, those engaged in signal detection must deploy a wide-angle lens for environmental change, to sense changes beyond the interest in a particular sector. When possible it is best to engage in a 360-D scanning of changes affecting not only the organization itself, but also its customers and its suppliers, or even the suppliers of the suppliers.

2. The conduct of experiments to determine how specific innovations may impact the firm, by creating future streams of revenues and profits. Regular wellplanned experiments in the real world are often expensive and time consuming. Sometimes they may also be very risky. However, it is often possible to conduct experiments in virtual worlds, as has been done by a number of firms like retailer Tesco's virtual supermarket or Proctor \& Gamble. It is often preferable for a firm to experiment with "actions-on-the margin". This means that during ongoing operations, while executing a firm's present strategy, management attempts selected variations in product or process design, as well certain variations in the business model and selecting for further development the most promising ones. The big advantages of small experiments on the margin include low cost in trying out new ideas, say new packaging, low risk and considerable learning.

3. Expanding the innovation space, by considering a wider range of innovations beyond the conventional focus on a firm's value chain. it is possible and often desirable to go beyond the visible and tangible factors to those that affect an organization's performance in less direct ways. As shown in Figure 3 two avenues for exploration are the horizontal axis related to the value-chain and the vertical axis related to the intangible variables (Dervitsiotis, 2010 ). 
Fig. 3: The horizontal and vertical dimensions of full-spectrum innovation

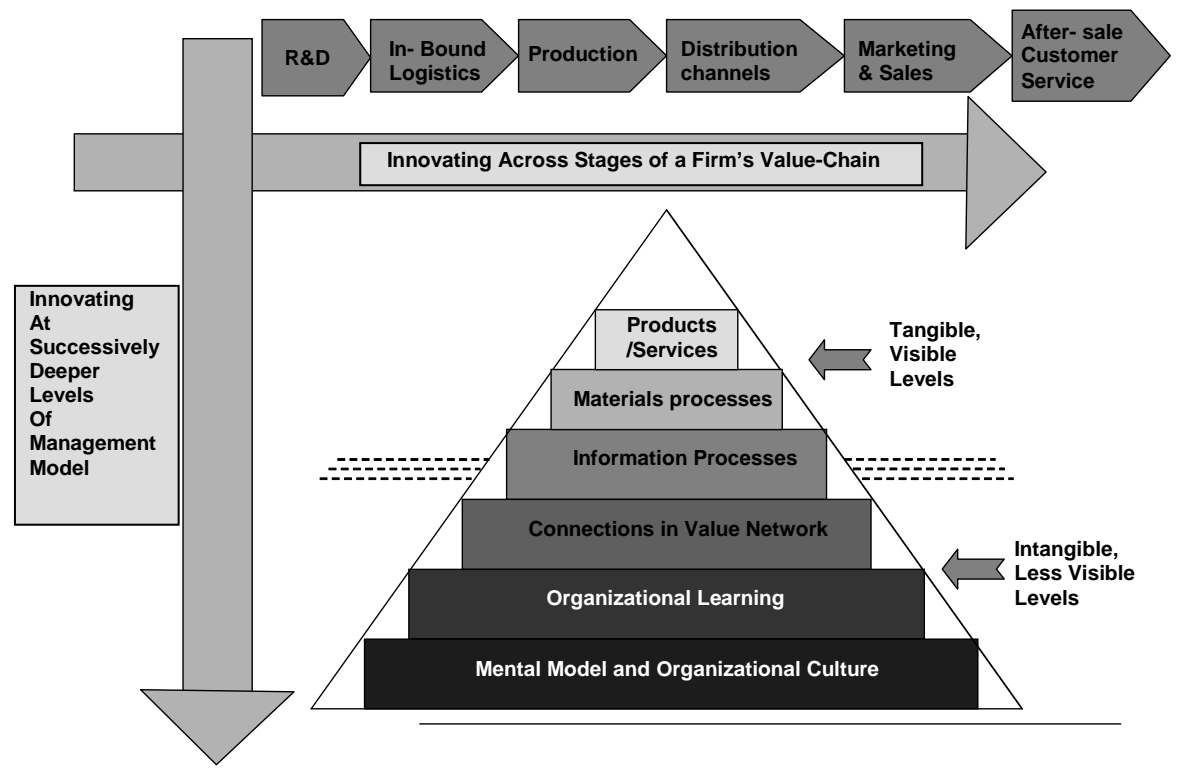

Source: Authors' elaboration

The pursuit of successful innovations involves both frequent incremental improvements, i.e. a faster chip, or greater safety in a surgical procedure, and less frequent highly disruptive innovations, such as the personal computer, the cell phone or a new procedure for human organ transplants. This disruptive kind of innovation is strategic in nature and can have dramatic effects, sometimes creating new industries that change the business landscape, as in the case of online selling for amazon.com (Christensen, 1998).

Increasing the quality of innovations requires a set of needed attitudes in the firm that are often missing in firms operating under conventional management.

1. Diversity of members in each team in terms of education and cultural backgrounds, that will facilitate multiple or alternative interpretations.

2. A healthy attitude toward risk from experimenting with new untested ideas on product, like ecological packaging, or process design adjustments for less pollution.

3. The acceptance of failure and certain costs, as the inevitable price for learning how best to cope with a complex, ever changing, uncertain environment.

As for every process there is a need to have a suitable innovation effectiveness index to evaluate how the approach used achieves the organization's goals. In a broad sense this index looks at the results of the total innovation investment and effort versus the net change in revenues and profits over a sufficient long period to avoid short-term myopia. 
To achieve high-levels of quality of innovation, a business firm's capability to innovate successfully, as with Apple Computer, is now becoming the key to survival in the presence of persistent waves of change. This rests primarily on the quality of an organization's innovation process, which in turn depends on having a leadership vision to excel now and in the future, on management's discipline to maintain flexibility, and on an organization culture in regards to maintaining a climate of trust, willingness to experiment, a healthy attitude towards risk, tolerance for failure, and an ability to learn rapidly and at a low cost from any failures (Dervitsiotis, 2011a).

As a rule, there are four fundamental requirements for an organization's innovation process to be effective. First is the ability to sense promptly and accurately any emerging value-creation opportunity by interpreting correctly incoming weak signals from changes in the environment. This can be done using human intuition or data mining. Once such weak signals have become clear to the whole industry, it is too late for a single company to exploit effectively a new opportunity and gain and maintain a distinct competitive advantage. The timing for introducing Apple's iTunes platform versus similar ones by competitors (Sony, Samsung, and others), offers a significant lesson of the importance of correct early detection and interpretation of the weak signals provided earlier by the Napster ${ }^{\circledR}$ experience of free music downloads. The second requirement is the ability for effective execution of the innovation, frequently accounting for up to $99 \%$ of the total effort, to bring a good innovation idea to market both rapidly and at a low cost (Govindarajan and Trimble, 2010 ). The third requirement is to strive at all times to maintain an overall balance in the pursuit of innovation. This includes:

1. A balance between incremental and disruptive (radical) innovation projects

2. A balance between the supply and demand of new ideas, after the commercialization stage.

3. A balance between internally (i.e. R\&D initiated) and externally or marketdriven projects.

\section{Quality of the organization design}

In the presence of continual change creating greater uncertainty and complexity, the second most critical kind of quality in the adaptive TQM framework is the quality of a firm's organizational design. This quality is evaluated by how well this architecture is suited to the prevailing and emerging environmental conditions.

The first important step involves the distinction between the formal and the informal parts of an organization. When an organizations is first started its architecture defines its various parts and their relationships to each other based on key functions (production, marketing, finance, etc. ) and legal or other requirements. These are designed to achieve specific objectives of the firm for its stakeholders. These structures are visible, are well documented in an organizational chart and give an overview of the organization as a "machine". After some time of operation, we 
observe the emergence of a "shadow" or informal organization complementing the formal organization (see Figure 4). This shadow part is very real human-based component. It is invisible, intuitive, adaptive and creative in order to cope with emerging complexity both in the environment and inside (Brown and Dunguid, 2000), rather than described by clear-cut charts of authority and responsibility, the informal organization is defined by a network of social relationships, responding to everyday conditions and represent it the living entity rather than the machine view of the firm.

Fig. 4: Increasing gap between designed and informal human structures

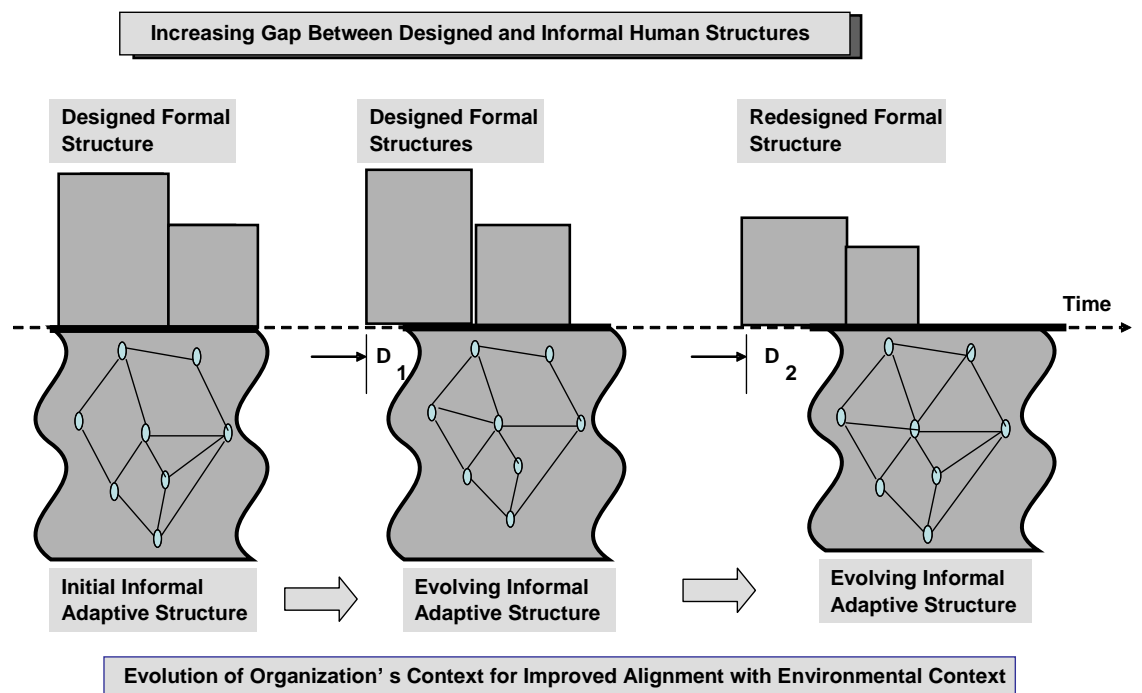

Kostas N. Dervitsiotis

Source: Authors' elaboration

As the change in the environment occurs faster ahead of any internal adjustments, the formal structures stay in place longer than needed often impeding the conduct of business with optimum performance. These delays increase the gaps between the formal and informal structures with the latter better in touch with external changes affecting the organization (see Figure 4 ).

Furthermore, in developing a more effective organizational design we must continually re-evaluate the "core" versus the "edge" parts (see Figure 5).

It is critical for leadership to recognize that the pressure for organizational change and often the source of good ideas for implementing new wealth-creation innovations originate at the "edge." At the boundary of an organization, people can sense more quickly the weak signals from the environment, compared with those at the well-established functions at the "core," who are preoccupied mainly with making existing products better, cheaper, and faster. 
The "core" includes all the key business functions that generate current revenues and profits (production, marketing, and others). These usually dominate business strategy development and execution. The "edge" refers to the parts of the organization at its boundary which are continually exposed to change signals from the environment. These can sense directly ongoing or oncoming changes likely to affect future wealth-creation opportunities and future performance. Among others, the "edge" includes people in sales dealing directly with customers, those in maintenance or engineering receiving customer feedback on how products fail in usage, or those in the supply chain who can detect rapidly "disconnects" in a supplychain affecting the smooth flow of customer orders. Recently, the supply-chain of computer components made in Thailand were severely disrupted from extensive flooding of factories in November 2011, creating shortages of hard disks and other parts, and posed great pressure on production schedules. Early signal detection of the disruption was valuable to computer manufacturers in seeking alternative supply sources to cover the shortfall.

Fig. 5: Understanding the roles of the organizational design "core" and the "edge"

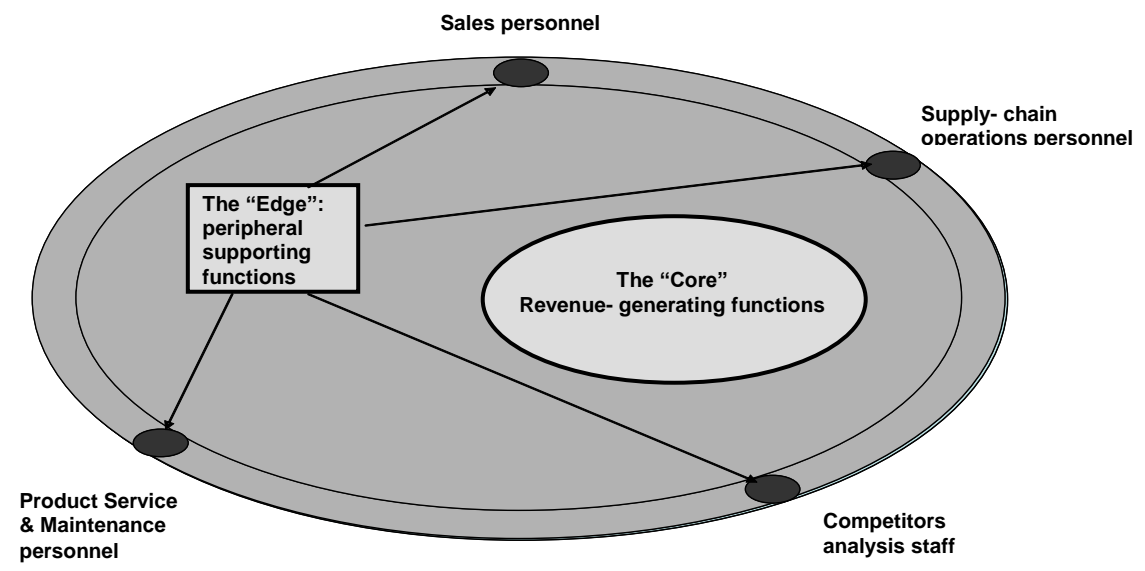

Source: Authors' elaboration

Another critical step in organization design is to redefine the role of leadership, in terms of its involvement and contribution in every part of the organization. In Figure 5 we note that as a firm operates in a more complex environment, especially one with the uncertainty and interconnectivity of the global economy, its management must encompass not only the capability to achieve the quality of product and process needed in a stable environment, but also the quality of its innovation process to explore new opportunities for value creation in emerging conditions and the quality of adapting continually its organizational architecture for optimal fitness in emerging business landscapes. In short, organizations must continually experiment to identify the best kinds of differentiation to maintain a 
competitive edge and the ability to integrate new organizational components and functions, so as to coordinate its operations smoothly and efficiently.

Gary Hamel points out that in today's conditions of rapid change, the concentration of leadership at the top of the pyramid creates insurmountable obstacles in creating adaptive organizations for the "creative economy". This comes about because a leadership concentrated at the top lacks ".. the needed intellectual diversity, the bandwidth and the time to make all the needed critical decisions..." As a result most needed changes often come too late, are infrequent and convulsive (Hamel, 2013 ). This leadership organization-wide deficit can be corrected by a change in the organization design similar to that made in the 1960's by Toyota Motors. Toyota implemented a breakthrough organization design innovation by making all frontline employees responsible for the quality of what they produced, rather than having a central staff function responsible. Toyota provided the needed training in statistical control and other methods to enable quality control at the points most suitable for improvements.

Fig. 6: The leadership challenge in the 21st century

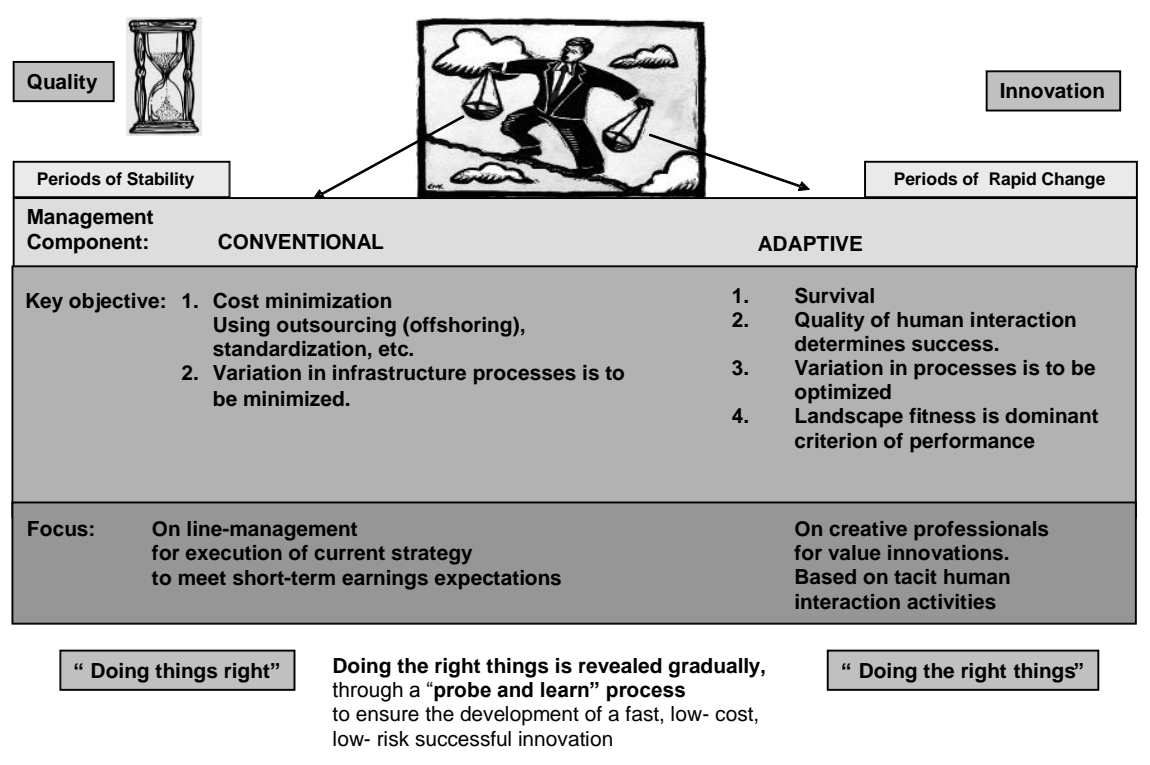

Source: Authors' elaboration

Figure 6 summarizes the complementary nature of the conventional management approach for short-term excellence (doing things right) and the innovative adaptive approach for long-term excellence (doing the right things). The focus of the first is the line management of the organization concerned with making existing products/services better, faster and cheaper, while for the long-term the focus is the development of value innovations that will generate future revenue and profit 
streams through a "probe and learn" process that will guarantee a low-risk, low cost exploration of promising innovations.

A firm's organization design fitness enables it to blend well with an everchanging business landscape (customers, suppliers, competitors and others), through modular components that permit effective loose coupling with other firms in a supply chain or its business ecology niche (Brown \& Haegel, 2005 ). Toyota's ${ }^{\mathrm{TM}}$ recent failure with the car accelerator problems had a huge cost on its finances and its sterling reputation as a global leader in quality; this is a typical example of not having an effective organizational design, by having omitted regional managers' direct feedback worldwide (the "edge") in its global information system. This proved to be a critical deficiency in providing prompt feedback on accident reports from car accelerator failures in the regions because such critical information was sent to the headquarters in Japan-to the "core" (Cole, 2011). Examples of organizational design innovations to cope with conditions created by the present global economic crisis include partnering with customers, suppliers or even competitors.

\section{Considerations for improving organizational design}

In addressing the challenge of improving the organizational design it is important to begin with adherence to certain fundamental design principles, i.e. seeking to maintain transparency, accountability, meritocracy and seeking natural leaders.

Great attention must be given to all information processes for planning coordination and control without inhibiting creativity and readiness to change (see Hamel, 2013).

Similar innovations, as the one developed by Toyota for a new approach to quality Control, may be possible by moving much special expertise, for example maintenance to lower levels, rather than special functions at the top. Furthermore, leadership which is in short supply below the top of the pyramid must be diffused so that responsibility and initiative are encouraged at lower levels in teams working at the "edge" parts of the organization, which need to respond fast to changes they encounter in the external environment. It is however essential that to diffuse leadership and special expertise to increasingly lower levels, the firm must provide the necessary training and information to those that need it and enable fast feedback loops to enable effective learning and make them accountable for their performance.

\section{Conclusions}

In today's global business landscape, the big challenge for leadership is to maintain a "bifocal view" on total performance-both for the short-run to generate much needed current revenue and to generate revenues in the future by developing needed incremental and radical innovations. The conventional approach to TQM 
was designed and refined to handle issues of performance improvements for conditions of relative stability that prevailed in the industrial era, up until the late 1970 's. This was primarily focused on the quality of an organization's products and processes. The new approach for TQM needed for conditions of rapid environmental change must shift its focus on how a firm can identify new sources of value-adding opportunities and new more fluid and effective organizational designs that facilitate optimal adaptation to new or emerging competitive landscapes in a global economy. Apple computers, Google ${ }^{\mathrm{TM}}$, 3M, GE, BMW, Samsung, Virgin Group and others provide good examples of such leadership capability, as they introduce both small, incremental improvements while continually experimenting and developing successful new radical innovations that capture the imagination of consumers worldwide.

\section{References}

BROWN J.S., DUGUID P. (2000), The social life of information, HBS Press, Cambridge, Mass.

CHRISTENSEN C. (1998), The Innovator's Dilemma, HBP, Boston.

COLE R. (2011), “Teaching Managers About Quality's Future by Learning from the Recent Past", Journal of Quality and Participation, October 2011, vol. 34, n. 3.

CONTI T. (2010), The dynamics of value generation and their dependence on an organization's internal and external value systems, Total Quality Management \& Business Excellence, vol. 21, n. 9-10.

DERVITSIOTIS K. (2012), "An Innovation-based Approach for Coping with Increasing Complexity in the Global Economy", Total Quality Management \& Business Excellence, vol. 23, n. 9, September, pp. 997-1011

DERVITSIOTIS K. (2011a), "The challenge of adaptation through innovation based on the quality of the innovation process", Total Quality Management \& Business Excellence, vol. 22, n. 5-6.

DERVITSIOTIS K. (2011b), “The New Imperative for Leadership :Advancing from Quality to Innovation", Journal of Quality and Participation, October 2011, vol. 34, n. 3.

DERVITSIOTIS K. (2010), "Developing Full-Spectrum Innovation Capability for Survival and Success in the Global Economy", Total Quality Management \& Business Excellence, vol. 21, n. 2, February 2010, pp. 157-168.

DERVITSIOTIS K. (2007), "On Becoming Adaptive: The New Imperative for Survival and Success in the $21^{\text {st }}$ Century", Total Quality Management \& Business Excellence, vol. 18 , n. 1-2.

DERVITSIOTIS K. (2003), "The pursuit of sustainable excellence: guiding transformation for effective organizational change", Total Quality Management, vol. 14, n. 3.

GALVIN J., HEXTER J., HIRT M. (2010), "Building a second home in China", McKinsey Quarterly, (mckinseyquarterly.com ), McKinsey \& Company, pp. 1-19.

HAMEL G. (2013), "Leaders everywhere: A conversation with Gary Hamel", McKinsey \& Company Newsletter, May 21.

GOVINDARAJAN V., TRIMBLE C. (2010), The other side of innovation, HBP.

PORTER M. (1985), Competitive Advantage, Free Press. 
